\title{
Global pattern of ecosystem respiration tendencies and its implications on terrestrial carbon sink potential
}

Peixin $\mathrm{Yu}$

Tao Zhou ( $\nabla$ tzhou@bnu.edu.cn )

Hui Luo

Xia Liu

Peijun Shi

Jingzhou Zhang

Yajie Zhang

Peifang Zhou

Yixin $\mathrm{Xu}$

\section{Research Article}

Keywords: ecosystem respiration, deep learning, spatial patterns, change trends, SPEl, carbon sink potential

Posted Date: December 3rd, 2021

DOI: https://doi.org/10.21203/rs.3.rs-1116960/v1

License: (c) (1) This work is licensed under a Creative Commons Attribution 4.0 International License.

Read Full License 


\section{Abstract}

As the largest component of carbon export from terrestrial ecosystems, ecosystem respiration (RECO) determines the carbon stock changes in terrestrial ecosystems. It is essential to accurately simulate the response of RECO to climate change. In this study, by constructing an optimal deep learning model for simulating global-scale RECO, we found that there is a 1-2 years' lagged response of RECO to changes in water conditions and an inconsistency in carbon input (NPP) and output (RECO) trends. The NPP growth trend in global terrestrial ecosystems is greater than that of RECO, with a trend showing increasing carbon sinks, particularly in the northern extra-tropics; while the carbon sink capacity of tropical regions has gradually saturated, showing that the changing trend of RECO is close to that of NPP, which poses a potential risk to the sustainable carbon sink capacity of global ecosystems in the future.

\section{Introduction}

Ecosystem respiration (RECO) is the process by which all organisms in an ecosystem convert organic carbon to $\mathrm{CO}_{2}$. It includes autotrophic respiration, which is generated by plant respiration, and heterotrophic respiration, which is generated by the decomposition of animals and microorganisms in the soil (Chapin, $\mathrm{FS}, 2012$ ). As the largest component of $\mathrm{CO}_{2}$ released into the atmosphere by terrestrial ecosystems, RECO together with vegetation productivity controls the carbon balance of terrestrial ecosystems (Yvon-Durocher et al., 2012). Under the influence of climate change, the carbon balance of terrestrial ecosystems has been significantly perturbed. On the one hand, global warming and $\mathrm{CO}_{2}$ fertilization effects will prolong the vegetation growth period, increase vegetation productivity, and enhance $\mathrm{CO}_{2}$ uptake (Bellassen and Luyssaert, 2014); on the other hand, global warming will accelerate permafrost melting, enhance ecosystem respiration, and release more $\mathrm{CO}_{2}$ into the atmosphere (Koven et al., 2011). Studies have shown that carbon emissions from terrestrial ecosystems continue to increase in future scenarios (Trumbore et al., 2006; Cox et al., 2000). In the long run, it may exceed or offset the increase in vegetation productivity, reducing the carbon sink capacity of terrestrial ecosystems and posing a significant risk to global ecosystems (Dixon et al., 1994; Luyssaert et al., 2007).

Many factors affect ecosystem respiration, such as temperature, water availability, vegetation productivity, and external carbon input (Gu et al., 2008; Mahecha et al., 2010a). Specifically: (1) Temperature, on the one hand, directly affects the vegetation respiration rate and microbial decomposition rate. In the short term, the respiration rate and microbial enzyme activity increase exponentially with increasing temperature (Lloyd and Taylor, 1994; Johnston et al., 2021). On the other hand, temperature affects respiration indirectly by affecting the photosynthesis of vegetation and changing the magnitude of vegetation productivity, which determines the quantity and quality of organic matter input to the soil. (2) Water availability. The respiration rates are lower in water-deficient environments because water deficiency can inhibit respiration through microbial drought stress and substrate limitation (Davidson et al., 2006). The respiration rates increase with increasing moisture until environments become saturated and anaerobic, which once again inhibits respiration rates (Haynes, 
1986; Hursh et al., 2017). (3) Vegetation productivity determines the quantity and quality of organic matter input to the soil and influences the rate of soil respiration (Janssens et al., 2001). In addition, studies have shown that plant respiration and vegetation productivity remain in essentially fixed ratios across ecosystems, at about half of total vegetation primary productivity GPP (48-60\%, Ryan et al., 1994; Landsberg and Gower, 1997). However, the uncertainty of this ratio is larger due to various factors (22$79 \%$, Collalti et al., 2019). (4) External carbon input includes vegetation litter and organic carbon stored in the soil. Vegetation litter is mainly determined by the growth of vegetation from the current year, while soil organic carbon is the product of long-term accumulation in the ecosystem, and they both are the nutrients that supply soil microorganisms for decomposition (Curiel Yuste et al., 2007; Chapin, FS, 2012).

One of the consequences of climate warming is the increase in precipitation and evapotranspiration, leading to an intensification of the water cycle. It greatly increases the degree of precipitation variability and affects the respiration rate of ecosystems, which can ultimately disrupt the carbon balance of terrestrial ecosystems (Dai et al., 2004; IPCC, 2013). Although many studies have concluded that respiration is less sensitive to changes in water than photosynthesis (Schwalm et al., 2010; Shi et al., 2014; Li et al., 2017), the RECO determines the amount of carbon output from terrestrial ecosystems, therefore, even small changes to RECO are critical and deserve more attention (Xu et al, 2004; AndersonTeixeira et al., 2015; Jung et al., 2017). In addition, studies have shown that there is a significant lagged response of respiration to water condition changes (Verburg et al., 2005; van der Molen et al., 2011) and the lag time of respiration may be longer than vegetation productivity. This may also be one of the reasons why the response of respiration to moisture changes is less pronounced than that of photosynthesis. After long-term field observations, Arnone III et al. (2008) found that there is a one-year lag time in respiration response to drought, resulting in a longer time for the ecosystem carbon sink to recover to its original level. While considering that the raw materials for soil respiration mainly come from the litter on the ground, Brando et al. (2008) found by isotope measurements that there is a two-year interval between the fall of leaves and the release of carbon dioxide by soil decomposition.

Currently, there are two main types of methods to study the effect of water on RECO. The first is statistical models (Yuste et al., 2005; Davidson et al., 2006), which simulate the effects of factors by constructing relationships between RECO and temperature, precipitation, NPP, etc. These models are simple, convenient, and less computationally intensive, however, they involve fewer variables and have limited ability to explain the process mechanism. Moreover, they are more suitable for analyzing the effects of individual factors. The second is process models, which simulate RECO and assess the effect of water conditions by modeling carbon and water cycle processes. These models have the advantage of achieving a representation of the process mechanism (Running and Hunt, 1993; Raich et al., 1991). However, although process models attempt to reproduce the processes in the terrestrial carbon cycle through detailed parameters and complex structures, the models' structures still rely on human experience. The processes that are not yet understood or discovered are not addressed in the models (Reichstein et al., 2019). For example, the lagged effect of water on RECO has not been considered, subsequently reducing the effectiveness of the model simulations. 
In recent years, deep learning has been increasingly applied to ecology. Compared with traditional statistical and process models, it has a powerful data fusion capability which can combine massive remote sensing data to great advantage (Xiao et al., 2019), and has an autonomous learning capability which means the model structure no longer depends on human design. Furthermore, it is necessary to fully consider the environmental factors that may affect RECO in conjunction with ecological mechanisms before an experiment and place them as variables into the model. It is also possible to assess the effects of environmental factors by controlling the input variables and evaluating accuracies. This approach can circumvent problems from process models in terms of structural design and parameterization.

At present, there is no definite conclusion regarding the optimal time scale of lagged effect of water on RECO, and few existing models consider this aspect. Therefore, with the help of data fusion ability and autonomous learning ability of deep learning, this study intends to incorporate various factors affecting RECO, such as temperature, precipitation, radiation, vegetation productivity, and soil organic carbon, into a deep learning model. At the same time, previous water conditions-at different time scales-are introduced into the model to investigate the lagged effect of water on RECO and its optimal time scale. The standardized precipitation evapotranspiration index (SPEI) is widely used as an effective indicator of water balance since it combines the effects of temperature and precipitation; moreover, the flexibility of its time scale is advantageous in studying the effect of water conditions on different timescales (VicenteSerrano et al., 2013; Barnes et al., 2016). The selection of SPEl at an optimal time scale can better characterize the lagged effects of water conditions (Huang et al., 2015; Luo et al., 2016, 2018).

In this study, firstly, based on deep learning models, we integrated flux observation data with meteorological, remote sensing, and soil data, and selected December SPEls at different time scales (12, 24 , and 36 months) as explanatory variables to represent the lagged effect of water conditions to simulate RECO. Secondly, by comparing the improvement degree of multi-time scale SPEls (and its combination) on RECO simulation accuracies to evaluate the water lagged effect and its optimal time scale. Then, the optimal model was established to simulate the spatial distribution and interannual variations of global RECO from 2000 to 2018. Finally, by comparing with NPP, we analyzed the regional differences in the inconsistency of RECO and NPP change trends and their effects on terrestrial carbon sink potential.

\section{Results}

Simulation Results of RECO. In this study, we chose RECO observations from the FLUNET 2015 dataset (Pastorello et al, 2020) as a standard, combining meteorological, remote sensing, and soil data, and used a convolutional neural network (CNN) to simulate RECO. According to different input parameters, six CNNs were established. During the experiment, each CNN model reached a stable state after 100,000 iterations with high accuracies in both the training and testing phases, indicating that the model did not overfit during the training process (Table 1 ). 
The experimental results showed that the training accuracy $\mathrm{R}^{2}$ of CNN-ORIGIN (CNN1) was 0.979, CC was 0.988, RMSE was 0.098, and SDE was 0.093. When introducing SPEl at different time scales, respectively, it was found that the introduction of SPEI12 (December SPEI on 12-month time scale) did not improve the performance of the model, i.e., the simulation accuracy of CNN2 was not improved compared to that of CNN1. However, SPEI24 (December SPEI on 24-month time scale) and SPEI36 (December SPEI on 36month time scale) improved the model significantly. The training accuracy of CNN3 was 0.986 for $\mathrm{R}^{2}$, 0.991 for CC, 0.085 for RMSE, and 0.074 for SDE; the training accuracy of CNN4 was 0.987 for $R^{2}, 0.992$ for CC, 0.078 for RMSE, and 0.072 for SDE, all of which were improved compared to that of CNN1. This shows that there is no significant effect of water conditions in the current year on RECO, while the effect of water conditions in the previous 1-2 years is more obvious, indicating that there is a significant lagged effect on the response of RECO to water condition changes, with a time scale of 1-2 years. The effect of the model was optimized when SPEI12 and SPEI24 were added jointly, i.e., CNN5-which had the highest accuracy and included the water conditions of the current year and the previous year and could reflect the lagged effect of RECO on water condition changes. Therefore, in this study, CNN5 was taken as the optimal model CNN-SPElopt, and the results of this model were subject to subsequent analysis.

Table 1 CNN training results.

\begin{tabular}{lcccccc}
\hline CNN & CNN1 & CNN2 & CNN3 & CNN4 & CNN5 & CNN6 \\
Model & & & & & \\
\hline Input & Basic & Basic Data, & Basic Data, & Basic Data, & Basic & Basic Data, SPEI12, \\
& Data & SPEI12 & SPEI24 & SPEI36 & Data, & SPEI24, SPEI36 \\
& & & & SPEI12, & \\
& & & & SPEI24 &
\end{tabular}

\begin{tabular}{lcccccccc}
\hline Training & $\mathrm{R} \square$ & 0.979 & 0.972 & 0.986 & 0.987 & $\mathbf{0 . 9 9 0}$ & 0.983 & 1000 \\
& $\mathrm{CC}$ & 0.988 & 0.984 & 0.991 & 0.992 & $\mathbf{0 . 9 9 4}$ & 0.987 \\
& $\mathrm{RMSE}$ & 0.098 & 0.113 & 0.085 & 0.078 & $\mathbf{0 . 0 6 8}$ & 0.103 \\
\hline Testing & $\mathrm{R} \square$ & 0.979 & 0.974 & 0.986 & 0.988 & $\mathbf{0 . 9 8 9}$ & 0.982 & 0.986 \\
& $\mathrm{CC}$ & 0.988 & 0.985 & 0.991 & 0.993 & $\mathbf{0 . 9 9 4}$ & 0.103 \\
& $\mathrm{RMSE}$ & 0.096 & 0.114 & 0.084 & 0.079 & $\mathbf{0 . 0 7 0}$ & $\mathbf{0 . 0 6 4}$ & 0.085 \\
\hline
\end{tabular}

Note: Basic data contains: MAT (mean annual temperature), MAP (mean annual precipitation), PAR (photosynthetically active radiation), FAPAR (fraction of absorbed photosynthetically active radiation), LAL (leaf area index), NDVI (normalized difference vegetation index), NPP and SOC (soil organic carbon) from 0 to $30 \mathrm{~cm}$; $\mathrm{R} \square$ : coefficient of determination, CC: Lin's concordance correlation coefficient, RMSE: root mean square error, SDE: standard deviation of error; n: number of samples. 
The simulation results of CNN-SPElopt show that the mean value of global multi-year average RECO from 2000 to 2018 is about $0.87 \mathrm{~kg} \cdot \mathrm{C} \cdot \mathrm{m}^{-2} \cdot \mathrm{y}^{-1}$, and the maximum value is about $3.75 \mathrm{~kg} \cdot \mathrm{C} \cdot \mathrm{m}^{-2} \cdot \mathrm{y}^{-1}$. The highvalue areas are mainly distributed in tropical rainforest areas, followed by mid-latitude and mid-high latitude forest-covered areas. The lowest RECO values are found in areas covered with grass and shrub and high latitude areas in the northern hemisphere. Fig. 1(b) shows the global spatial distribution of the standard deviation (STDEV) of RECO from 2000 to 2018, which reflects the magnitude of interannual fluctuations of RECO. The mean value of global RECO STDEV is about $0.22 \mathrm{~kg} \cdot \mathrm{C} \cdot \mathrm{m}^{-2} \cdot \mathrm{y}^{-1}$, and the maximum value is $1.87 \mathrm{~kg} \cdot \mathrm{C} \cdot \mathrm{m}^{-2} \cdot \mathrm{y}^{-1}$.

To validate the CNN-SPElopt simulation results, we compared them with six commonly used process models. The mean value of RECO simulated by CNN-SPElopt is close to most models, but its standard deviation is much higher than others. It can be speculated that although the traditional process models can simulate RECO, the interannual fluctuations of RECO may be significantly underestimated by about $71 \%$ to $88 \%$.

To reveal whether these models can accurately reflect the interannual fluctuations of RECO, this study collected 173 observations from 30 sites of AmeriFlux (https://ameriflux.lbl.gov) and ChinaFlux (http://www.cnern.org.cn) to validate each model. First, by comparing the 173 observations with the simulated values of the models, we found that CNN-SPElopt had the highest accuracy and the smallest simulation error, with an $\mathrm{R}^{2}$ of 0.535 and an RMSE of 0.444 . While the $\mathrm{R}^{2}$ of the other models ranged from 0.002 to 0.468 and an RMSE from 0.475 to 0.856 (Fig. 2). Second, we calculated the standard deviation of the multi-year observations for each site and the standard deviation of the models' simulations and conducted a correlation analysis between the standard deviation of the observations and the standard deviation of the simulations (Fig. 3). The results show that the Pearson correlation coefficient between CNN-SPElopt and site observations is 0.475 , which is significantly correlated at the $p<0.01$ level. Moreover, the Pearson correlation coefficients between other process models and site observations are very low and some models even show a negative correlation. This indicates that among these models, only CNN-SPElopt can capture the interannual fluctuations of RECO because it is more consistent with the observed interannual fluctuations of RECO. The standard deviations of the other models' simulations are generally low and inconsistent with the site observations, indicating that these models would substantially underestimate the interannual fluctuations of RECO.

Spatial Patterns and Changing Trends of RECO and NPP. The CNN-SPElopt shows that the global average RECO has a significant increasing trend $(p<0.01)$ with climate change. Spatially, $54.92 \%$ of the global RECO shows an increasing trend, while $45.08 \%$ shows a decreasing trend. This indicates that the global RECO is dominated by growth.

The global average NPP also shows a significant increasing trend $(p<0.01)$, but the growth rate of NPP (slope of 0.154 ) is higher than that of RECO (slope of 0.142 ). In terms of spatial distribution, NPP shows a significant increasing trend in most of the global regions, except for the Amazon region. Globally, $73.35 \%$ of the NPP shows an increasing trend and $26.65 \%$ shows a decreasing trend. This indicates that 
although the growth trends of global average RECO and NPP are similar, the proportion of increasing NPP is higher than that of increasing RECO, and the carbon sink potential of the global terrestrial ecosystem generally shows an increasing trend.

The land area of the northern extra-tropics $\left(30^{\circ} \mathrm{N} \sim 90^{\circ} \mathrm{N}\right)$ accounts for about $60 \%$ of the world, with extensive forest cover and high carbon sink potential. On the one hand, influenced by the warming and humidification of climate and the effect of $\mathrm{CO}_{2}$ fertilization, the growth period of boreal vegetation is prolonged and vegetation productivity is increasing (Bellassen and Luyssaert, 2014), which enhances terrestrial carbon sink capacity. On the other hand, the boreal permafrost contains a large amount of soil carbon, and global warming will accelerate the permafrost melt and release $\mathrm{CO}_{2}$, which also risks enhancing terrestrial carbon emissions (Koven et al., 2011). The CNN-SPElopt results show that the average RECO in the northern extra-tropics is significantly increased $(p<0.01)$. The spatial distribution of RECO is dominated by growth, with $55.69 \%$ of RECO showing an increasing trend and $44.31 \%$ shows a decreasing trend.

Meanwhile, MODIS NPP also shows a significant increasing trend $(p<0.01)$ in the northern extra-tropics, however, the growth rate of NPP (slope of 0.152 ) is much higher than that of RECO (slope of 0.107 ). In terms of spatial distribution, $80.12 \%$ of NPP is increasing, while $19.88 \%$ of NPP is decreasing. The increasing proportion of NPP is much larger than that of RECO. In other words, the NPP in the northern extra-tropics shows a substantial increase, while RECO does not increase as significantly. The carbon sink potential of this region has a gradual increase trend dominated by the growth of NPP.

The tropics $\left(30^{\circ} \mathrm{N} 30^{\circ} \mathrm{S}\right)$, which covers about $36 \%$ of the global land area, contains the largest tropical rainforests and the highest vegetation productivity in the world, as well as the largest carbon sink. CNNSPElopt shows that RECO in this region has a significant increasing trend $(p<0.01)$. In terms of spatial distribution, $53.53 \%$ of RECO shows an increasing trend, while $46.47 \%$ shows a decreasing trend.

NPP in the tropics also shows a significant increasing trend $(p<0.01)$ and the growth rate of NPP is close to that of RECO (slope of NPP is 0.122 and RECO is 0.114 ). Spatially, $62.05 \%$ of NPP shows an increasing trend and $37.95 \%$ shows a decreasing trend. The percentage of increasing RECO in the tropics is close to that in the northern extra-tropics, however, the percentage of increasing NPP is much lower than that in the northern extra-tropics. Although the increasing area of NPP in the tropics is larger than that of RECO, the excess area is less than $10 \%$. The advantage of carbon sink growth in the tropics is weaker than that in the northern extra-tropics where the area of increasing NPP is about 25\% more than that of RECO.

The southern extra-tropics $\left(30^{\circ} \mathrm{S}\right.$ to $\left.90^{\circ} \mathrm{S}\right)$ has a small land area covered by vegetation, accounting for only about $4 \%$ of the globe except for the Antarctic continent. The RECO in this region still shows an increasing trend, but with a lower significance $(p<0.1)$ than other regions. Spatially, $56.28 \%$ of RECO shows an increasing trend, while $43.72 \%$ of RECO shows a decreasing trend.

The NPP in the southern extra-tropics shows an increasing trend, with a slightly lower significance $(p<$ 0.05 ) than other regions. Spatially, $71.90 \%$ of NPP shows an increasing trend, while $28.10 \%$ shows a 
decreasing trend. The percentage of increasing NPP in the southern extra-tropics is larger than that of RECO-about 15\% more. However, because of the small land area of this region, it has less impact on the global carbon sink.

In addition, we calculated the proportions of spatial grids where RECO and NPP changed in the same and opposite directions both globally and regionally (Fig. $5 \mathrm{c}$ and Table 3). The areas where NPP increased indicated that the vegetation in these areas is in good condition. The areas where NPP increased and RECO decreased are obvious carbon sinks with the greatest carbon sink capacity. The areas where NPP decreased implied vegetation death or reduced productivity. A decrease in NPP and an increase in RECO means that these areas are at risk of becoming carbon sources. Presently, the results show that the global carbon sink potential of terrestrial ecosystems is increasing, as nearly half of the areas where NPP and RECO are increasing simultaneously (41.08\%) and the proportion of NPP increasing and RECO decreasing is also higher (32.28\%). The proportions of the other two scenarios are lower, $13.91 \%$ are NPP decreasing and RECO increasing, and $12.73 \%$ are both NPP and RECO decreasing.

The northern extra-tropics has $44.87 \%$ of areas where both NPP and RECO increased and $35.57 \%$ of areas where NPP increased and RECO decreased. Both are lower in the tropics, with $35.06 \%$ of the area where both NPP and RECO increased and $27.27 \%$ of the area where NPP increased and RECO decreased. The proportion of area with increasing carbon sink potential is much higher in the northern extra-tropics than in the tropics.

On the contrary, in the northern extra-tropics, $10.93 \%$ of areas have decreasing NPP and increasing RECO, and $8.62 \%$ has a decrease in both. These regions are mainly concentrated on the west coast of the United States, eastern North America, central Europe, and central and southwestern Russia. In the tropics, $18.49 \%$ of areas have decreasing NPP and increasing RECO, and $19.17 \%$ of areas have a decrease in both. These two are the highest in the tropics. This means that the regions with the highest carbon source risk are most concentrated in the tropics, mainly in the southern tip of North America, Amazonia, eastern Brazil, central Africa, eastern India, southeastern China, and Southeast Asia.

In summary, the growth trends of global RECO and NPP show imbalances. First, there is an imbalance between the growth rate of RECO and NPP; moreover, the growth rate of NPP is larger than that of RECO, and the proportion of NPP increasing area is also higher than that of RECO, which contributes to maintaining the carbon sink of the global terrestrial ecosystem in an increasing trend. Second, the carbon sink potential of different regions is unbalanced. In the northern extra-tropics, the growth rate of NPP is significantly larger than that of RECO, and the proportion of NPP increasing area is also the highest. Furthermore, in the tropics, the growth rates of RECO and NPP are markedly close, and the proportion of NPP increasing area is much lower than that in the northern extra-tropics.

Table 2 Increasing or decreasing proportions of global and regional RECO and NPP. 


\begin{tabular}{cc|cc|cc|cc|cc}
\hline & & \multicolumn{2}{|c|}{ Global } & \multicolumn{2}{c|}{$\begin{array}{c}\text { Northern Extra- } \\
\text { tropics }\end{array}$} & \multicolumn{2}{c}{ Tropics } & \multicolumn{2}{c}{$\begin{array}{c}\text { Southern Extra- } \\
\text { tropics }\end{array}$} \\
\hline & & Increase & Decrease & Increase & Decrease & Increase & Decrease & Increase & Decrease \\
\hline RECO & & $54.92 \%$ & $45.08 \%$ & $55.69 \%$ & $44.31 \%$ & $53.53 \%$ & $46.47 \%$ & $56.28 \%$ & $43.72 \%$ \\
& $p<$ & $13.01 \%$ & $8.37 \%$ & $13.12 \%$ & $7.88 \%$ & $12.72 \%$ & $8.99 \%$ & $13.90 \%$ & $9.60 \%$ \\
& 0.1 & & & & & & & & \\
\hline \multirow{2}{*}{$\mathrm{NPP}$} & & $73.35 \%$ & $26.65 \%$ & $\mathbf{8 0 . 1 2} \%$ & $19.88 \%$ & $\mathbf{6 2 . 0 5 \%}$ & $37.95 \%$ & $71.90 \%$ & $28.10 \%$ \\
& $p<$ & $30.13 \%$ & $6.06 \%$ & $30.88 \%$ & $2.23 \%$ & $29.93 \%$ & $12.74 \%$ & $21.38 \%$ & $4.49 \%$ \\
& 0.1 & & & & & & & & \\
\hline
\end{tabular}

Table 3 Proportions of global and regional RECO and NPP in the same and opposite change directions.

\section{Global Northern Extra-tropics Tropics Southern Extra-tropics}

\begin{tabular}{ccccc}
\hline NPP+RECO+ & $41.08 \%$ & $\mathbf{4 4 . 8 7 \%}$ & $35.06 \%$ & $41.34 \%$ \\
\hline NPP+RECO- & $32.28 \%$ & $\mathbf{3 5 . 5 7 \%}$ & $27.27 \%$ & $30.56 \%$ \\
\hline NPP-RECO+ & $13.91 \%$ & $10.93 \%$ & $\mathbf{1 8 . 4 9 \%}$ & $14.94 \%$ \\
\hline NPP-RECO- & $12.73 \%$ & $8.62 \%$ & $\mathbf{1 9 . 1 7 \%}$ & $13.15 \%$ \\
\hline
\end{tabular}

Global and Regional Carbon Sink Capacities and Potential Risk Assessment. In this study, the difference between the NPP growth rate and RECO growth rate at each spatial grids was calculated (Fig. 6) to quantitatively assess the global and regional capacities and potential risk of carbon sink. The areas dominated by NPP growth are carbon sink potential areas (the area where NPP grows faster is larger than the area where RECO grows faster), and the areas dominated by RECO growth are carbon source risk areas (the area where NPP grows faster is smaller than the area where RECO grows faster). As shown in Fig. $6,65.59 \%$ of the global areas have a faster NPP growth rate, and $34.41 \%$ are areas with a faster RECO growth. This indicates that the global terrestrial ecosystem has a certain capacity of carbon sink dominated by NPP growth.

In the northern extra-tropics, $69.33 \%$ of the areas have a faster NPP growth rate and $30.67 \%$ of the areas have a faster RECO growth rate. The northern extra-tropics is clearly dominated by NPP growth, and the capacity of the carbon sink is gradually increasing. The regions where the NPP growth rate is significantly higher than that of RECO are concentrated in northeastern China and most regions of Europe and North America. The regions where the RECO growth rate is significantly higher than the NPP growth rate are concentrated in central and southwestern Russia and central and eastern North America. The vegetation distributed in the northern extra-tropics is extensive and rich in types, such as deciduous broadleaf forest (DBF), evergreen coniferous forest (ENF), grassland (GRA), and savanna (SAV), all of which have high carbon sink capacities (Fig. 7a), implying that the northern extra-tropics has substantial carbon sink capacity.

In the tropics, the distribution of carbon sink potential areas is considerably uneven. On the one hand, in the Amazon and African rainforest areas, the growth rate of RECO is significantly higher than that of NPP, which has a greater risk of carbon source. In addition, the RECO growth rate is also higher in eastern 
India, southern China, and Southeast Asia. On the other hand, central South America, central Africa, some regions of China, and India also have obvious carbon sink areas, i.e., the NPP growth rate is higher than that of RECO. Specifically, $59.67 \%$ of the tropical areas are experiencing faster growth rates of NPP and $40.33 \%$ are experiencing faster growth rates of RECO. Although the tropics are still dominated by NPP growth, the dominance is less pronounced than that of the northern extra-tropics. The carbon cycle balance in the tropics has been severely disturbed in recent years, mainly due to the destruction of tropical rainforests and the fact that their carbon sink capacity has become saturated. Fig. 7a shows that the evergreen broadleaf forest (EBF), which is widely distributed in the tropics, has a smaller carbon sink capacity and the strongest capacity to release carbon by respiration among the many vegetation types. Several high-risk carbon source regions such as Amazonia, central African, and Southeast Asia, all of which are widely distributed in tropical forests, now have significantly reduced carbon sink capacity. This could cause a break in the global terrestrial ecosystem carbon cycle and threaten the entire planetary ecosystem.

In the southern extra-tropics, $62.19 \%$ have a faster NPP growth rate and $37.81 \%$ have a faster RECO growth rate. The carbon sink capacity is slightly more optimistic than that of the tropics. However, this region has less vegetation area, mainly grassland and shrubs, and contributes less to the global terrestrial ecosystem.

In addition, this study assessed the capacities of several major economies regarding their contributions to the global terrestrial ecosystem carbon sink, including the United States, China, the European region (except Russia), Brazil, and India (Fig. 7b). Among these countries and regions, China has the largest carbon sink capacity, followed by the U.S. and the European region, and Brazil and India have smaller carbon sinks. The United States and the European region have high forest cover and rich vegetation carbon stocks. However, as forests in these two countries are generally older and most ecosystems are highly mature, the growth potential of carbon sink is not prominent and is in a more stable state. Brazil, a country with a large tropical rainforest area, is no longer outstanding for its carbon sink, which is caused by the decrease in tropical rainforest area and the saturation of carbon sink capacity. Most notably, China and India both have large-scale greening areas subject to anthropogenic regulation, and together dominate the global trend of vegetation greening, however, their carbon sink capacities are vastly different. The expansion of greening in China is attributed to the national policy of returning farmland to forest and grassland, of which forests contribute $42 \%$, thus enhancing the carbon sink capacity. In contrast, $82 \%$ of greening in India comes from farmland, with forest greening accounting for only $4.4 \%$ (Chen et al., 2019). Furthermore, the respiration rate of farmland is relatively high and contributes minorly to the carbon sink, thus India has a weaker carbon sink capacity.

\section{Discussion}

In this study, the training and optimization of the CNN models revealed that the introduction of the SPEI of the current year did not optimize the model, indicating that RECO is not sensitive to the water condition of the current year. The effect of the model was improved when the SPEl of cumulative two years and 
cumulative three years were introduced, indicating that RECO has a sensitivity to the water conditions of the previous one to two years. It can be inferred that the effect of water condition on RECO has a one- to two-year lagged effect. Our experimental results suggest that RECO is not insensitive to water changes but to water changes in the current year, since it takes some time for changes in water conditions to be reflected in changes in RECO. Whereas studies have shown that vegetation productivity is most sensitive to water changes in the current year (Liu et al., 2021), there is also a lagged effect on vegetation productivity (Vicente-Serrano et al., 2013; Barnes et al., 2016), however, the lag time of RECO may be longer in comparison. This is because the changes in water conditions first act on vegetation growth, then the organic matter is imported into the soil and used for respiration decomposition. A process such as this takes some time (Brando et al., 2008), so the response of respiration to water changes will take a longer time. In addition, the organic matter decomposed by respiration is not all produced in the current year, but also includes organic matter stored by vegetation during previous years (Martínez-Vilalta et al., 2016), therefore, the vegetation growth conditions affected by previous water conditions will also respond to the current respiration. It follows that the lagged effect of water conditions has a more profound and complex impact on ecosystems and that the ecosystem carbon cycle balance takes longer to recover once it is perturbed by changes in water conditions (Arnone III et al., 2008). Therefore, it is essential to consider the previous water conditions when simulating RECO.

Based on the models' training results, we obtained an optimization model (CNN-SPElopt) with the highest accuracy for simulating RECO. The validation of CNN-SPElopt and commonly used process models with site observations show that CNN-SPElopt not only has the highest accuracy but can also accurately simulate the interannual fluctuations of RECO, compared with other process models that severely underestimate the interannual fluctuations. The deficiency of process models in simulating interannual fluctuations of RECO is an important factor leading to uncertainty in the simulation results of the carbon sink potential of global terrestrial ecosystems, which should be strengthened in future studies.

The comparison between changes in ecosystem carbon output (RECO) and carbon input (NPP) shows that during 2000-2018, under the combined influence of global climate change and human activities, both global RECO and NPP show an increasing trend, however, their increasing trends are in an unbalanced state. One is the imbalance between NPP growth rate and RECO growth rate, and the other is the imbalance of carbon sink potential among different regions.

The northern extra-tropics shows the greatest carbon sink potential, with the NPP growth increasing more rapidly and at a much higher rate than that of RECO. This is mainly due to the prolonged vegetation growing season in the mid and high latitudes of the northern hemisphere due to the influence of climate warming. Meanwhile, the higher atmospheric $\mathrm{CO}_{2}$ concentrations and the $\mathrm{CO}_{2}$ fertilization effect result in enhanced photosynthesis of vegetation, which ultimately leads to higher vegetation productivity (Bellassen and Luyssaert, 2014). The increase in NPP implies a better growth state of vegetation, with litter and dead plants being reduced, and less material being imported into the soil to supply microbial decomposition, thus inhibiting the increase in respiration. In addition, Reich et al. found that vegetation respiration in boreal regions is adaptive to climate warming (Reich et al., 2016). In that case, although 
RECO tends to increase during warming periods, the increase is not as pronounced as expected. Thus, the northern extra-tropics show an increasing carbon sink potential trend dominated by NPP growth.

NPP and RECO are also increasing in the tropics, however, the extent of NPP growth in the tropics is less pronounced than in the northern extra-tropics. On the one hand, it has been shown that the carbon sink capacity of tropical forests has reached saturation in the last decade or so (Hubau et al., 2020). In particular, the regions with tropical rainforest distribution, such as the Amazon, central Africa, and Southeast Asia, have a higher RECO growth rate and potential risk of carbon sources (Fig. 6). On the other hand, tree mortality has increased due to high-frequency extreme drought events (Lewis et al., 2011; Feldpausch et al., 2016), further leading to a decrease in forest carbon sink capacity. In addition, it has been shown that the $\mathrm{CO}_{2}$ fertilization effect, previously thought to be the most significant in the tropics, is not as significant as expected. Vegetation growth in the tropics is dominated by other factors, such as water utilization (van der Sleen et al., 2015; Rahman et al., 2019). Therefore, the decreasing carbon sink potential in the tropics implies that the tropics have gradually lost their dominant position in the carbon sink of global terrestrial ecosystems and have become a potential risk to global terrestrial ecosystems (Brienen et al., 2015). Therefore, protecting tropical rainforests from further destruction is, nowadays, the most urgent task.

In addition, national policy regulations can also have an impact on global carbon sinks. For example, Brazil, a country with large tropical rainforests, has no advantage in carbon sink growth, mainly due to deforestation (Turubanova et al., 2018). The U.S. and European regions have high-quality forest protection and more stable carbon sinks, however, the carbon sink potential is average due to the predominance of old-growth forests (Pregitzer et al., 2004). China has been implementing policies relating to returning farmland to forests and grassland since 1999. The greening area has been expanding and forest growth is right at a stage of high carbon sink capacity, which contributes significantly to carbon sinks. India has also seen a substantial increase in greening area, but the greening is mainly from agricultural land with high respiration rates, resulting in no significant improvement in India's carbon sink capacity.

\section{Methods}

Data sources and processing. Basic data for simulating RECO were selected according to the influencing factors of RECO, including climate, vegetation, and soil factors, specifically: (1) Climate indicators include mean annual temperature (MAT), mean annual precipitation (MAP), mean annual photosynthetically active radiation (PAR), and December SPEI on different time scales (12, 24, and 36 months); (2) vegetation indicators include the mean annual normalized difference vegetation index (NDVI), mean annual leaf area index ( $\mathrm{LAl}$ ), mean annual fraction of absorbed photosynthetically active radiation (FAPAR), and annual cumulative NPP; (3) soil indicators include soil organic carbon (SOC) from 0 to 30 cm. MAT and MAP are from CRU-TS 4.05 dataset (http://www.cru.uea.ac.uk/data), PAR is from GLASS product GLASS04B01 V42 (Cheng et al., 2014), SPEls are from the SPElbase V. 2.6 dataset (http://sac.csic.es/spei), NDVI is from the MODIS product MOD13A3 V006 (Didan, 2015), NPP is from the 
MODIS product MOD17A3HGF (Running and Zhao, 2019), LAl is from the GLASS product GLASS01B01 V50 (Xiao et al., 2014, 2016), FAPAR is from GLASS09E01 V50 (Xiao et al., 2015), and SOC is from the SoilGrids250m dataset (Hengl et al., 2017). Considering the spatial matching problem between flux sites and spatial data, and the efficiency of simulating global spatial data, all the raster data mentioned above were resampled to $0.05^{\circ}$ pixel size according to the nearest neighbor image method.

Model training and data analysis. The CNN used in this study is one of the most representative models in deep learning, which is based on artificial neural networks (ANN) and generates a deeper network structure through weight sharing and sparse connections. The CNN not only has a strong data fusion and autonomous learning ability, but it also reads information of neighborhood size and is able to retain certain geospatial structural features. The CNN constructed in this study contains three convolutional layers, three maximum pooling layers, and one fully connected layer. The input parameters include: MAT, MAP, PAR, FAPAR, LAI, NDVI, NPP, SOC00, SOC05, SOC15, SOC30, SPEI12, SPEI24, and SPEI36, which all take the longitude and latitude of each FLUXNET site as the central grid point, using a neighborhood of $3 \times 3$ in size. These data are transformed through layers, and finally output the predicted values by the ReLU activation function (Glorot et al., 2011). During the training process, the Adam algorithm (Kingma and $\mathrm{Ba}, 2015)$ was used for parameter optimization. The network parameters were continuously adjusted by minimizing the difference between the predicted and observed values. Until the difference was less than a certain threshold and no longer changed significantly, the training was complete.

In this study, we collected 1000 sample data. During the training process, for each iteration, the sample data was randomly allocated to the training set and the testing set at a ratio of 10:3. The training set was used to train the model, while the testing set was used to verify the model accuracy and monitor the model training process to prevent overfitting. At the end of the training, we took the average of the accuracy of the last ten iterations as the final training accuracy and testing accuracy. The accuracy of the model simulation was evaluated by the coefficient of determination $\left(R^{2}\right)$, Lin's concordance correlation coefficient (CC) (Lawrence and Lin, 1989), the root mean square error (RMSE), and the standard deviation of error (SDE).

In order to find the optimal time scale for the lagged response of RECO to water conditions, we designed six CNN models. The CNN1 model is without SPEl except for the base data (MAT, MAP, PAR, FAPAR, LAI, NDVI, NPP, SOC), i.e., the original model CNN-ORIGIN. In addition, in order to investigate whether there is a lag effect of RECO at certain time scales, SPEI12, SPEI24, and SPEI36 were introduced separately in CNN2, CNN3, and CNN4, respectively. The effects of previous water conditions on RECO at different time scales were evaluated by observing the improvement degree of these three models. SPEI12 and SPEI24 were added jointly in CNN5, and SPEI12, SPEI24, and SPEI36 were added jointly in CNN6. In this way, we can explore the optimal time scale and optimal combination of SPEls to obtain the model with the best performance. Based on the models' accuracy evaluation results, the optimal model CNN-SPElopt was selected to simulate the spatial pattern and interannual variation of global RECO from 2000 to 2018 and calculate the change rates of each grid point in the global spatial distribution from 2000 to 2018 . For the 
comparison between RECO and NPP, the values of RECO and NPP were z-score standardized according to Formula (1):

$$
\text { Value }_{z}=\frac{\text { Value }_{\text {origin }- \text { Value }_{\text {mean }}}}{\text { Value }_{\text {std }}}
$$

\section{References}

1. Anderson-Teixeira, K. J., Delong, J. P., Fox, A. M., Brese, D. A., \& Litvak, M. E. (2011). Differential responses of production and respiration to temperature and moisture drive the carbon balance across a climatic gradient in New Mexico. Global Change Biology, 17(1), 410-424. https://doi.org/10.1111/j.1365-2486.2010.02269.x

2. Arnone III, J. A., Verburg, P. S., Johnson, D. W., Larsen, J. D., Jasoni, R. L., Lucchesi, A. J., ... Schimel, D. S. (2008). Prolonged suppression of ecosystem carbon dioxide uptake after an anomalously warm year. Nature, 455(7211), 383-386. https://doi.org/10.1038/nature07296

3. Barnes, M. L., Moran, M. S., Scott, R. L., Kolb, T. E., Ponce-Campos, G. E., Moore, D. J. P., Dore, S. (2016). Vegetation productivity responds to sub-annual climate conditions across semiarid biomes. Ecosphere, 7, e01339. https://doi.org/10.1002/ecs2.1339

4. Bellassen, V., \& Luyssaert, S. (2014). Carbon sequestration: Managing forests in uncertain times. Nature News, 506(7487), 153. https://doi.org/10.1038/506153a

5. Bonan, G. B. (2008). Forests and climate change: forcings, feedbacks, and the climate benefits of forests. science, 320(5882), 1444-1449. https://doi.org/10.1126/science.1155121

6. Brando, P. M., Nepstad, D. C., Davidson, E. A., Trumbore, S. E., Ray, D., \& Camargo, P. (2008). Drought effects on litterfall, wood production and belowground carbon cycling in an Amazon forest: results of a throughfall reduction experiment. Philosophical Transactions of the Royal Society B: Biological Sciences, 363(1498), 1839-1848. https://doi.org/10.1098/rstb.2007.0031

7. Brienen, R. J., Phillips, O. L., Feldpausch, T. R., Gloor, E., Baker, T. R., Lloyd, J., ... Zagt, R. J. (2015). Long-term decline of the Amazon carbon sink. Nature, 519(7543), 344-348. https://doi.org/10.1038/nature14283

8. Chapin, F.S., Matson, P. A., Vitousek P.M. (2012) Principles of Terrestrial Ecosystem Ecology.

9. Chen, C., Park, T., Wang, X., Piao, S., Xu, B., Chaturvedi, R. K., ... Myneni, R. B. (2019). China and India lead in greening of the world through land-use management. Nature sustainability, 2(2), 122-129. https://doi.org/10.1038/s41893-019-0220-7

10. Cheng, J., \& Liang, S. (2014). Estimating the broadband longwave emissivity of global bare soil from the MODIS shortwave albedo product. Journal of Geophysical Research: Atmospheres, 119(2), 614634. https://doi.org/10.1002/2013JD020689 
11. Collalti, A., \& Prentice, I. C. (2019). Is NPP proportional to GPP? Waring's hypothesis 20 years on. Tree physiology, 39(8), 1473-1483. https://doi.org/10.1093/treephys/tpz034

12. Cox, P. M., Betts, R. A., Jones, C. D., Spall, S. A., \& Totterdell, I. J. (2000). Acceleration of global warming due to carbon-cycle feedbacks in a coupled climate model. Nature, 408(6809), 184-187

13. Curiel Yuste, J., Baldocchi, D. D., Gershenson, A., Goldstein, A., Misson, L., \& Wong, S. (2007). Microbial soil respiration and its dependency on carbon inputs, soil temperature and moisture. Global Change Biology, 13(9), 2018-2035. https://doi.org/10.1111/j.1365-2486.2007.01415.x

14. Dai, A., Trenberth, K. E., \& Qian, T. (2004). A global dataset of Palmer Drought Severity Index for 1870-2002: Relationship with soil moisture and effects of surface warming. Journal of Hydrometeorology, 5(6), 1117-1130. https://doi.org/10.1175/JHM-386.1

15. Davidson, E. A., Janssens, I. A., \& Luo, Y. (2006). On the variability of respiration in terrestrial ecosystems: moving beyond $\mathrm{Q}_{10}$. Global Change Biology, 12(2), 154-164. https://doi.org/10.1111/j.1365-2486.2005.01065.x

16. Davidson, E. A., Richardson, A. D., Savage, K. E., \& Hollinger, D. Y. (2006). A distinct seasonal pattern of the ratio of soil respiration to total ecosystem respiration in a spruce-dominated forest. Global Change Biology, 12(2), 230-239. https://doi.org/10.1111/j.1365-2486.2005.01062.x

17. Didan, K. (2015). MOD13A3 MODIS/Terra vegetation Indices Monthly L3 Global 1km SIN Grid V006 [Data set]. NASA EOSDIS Land Processes DAAC. Accessed 2021-08-23 from https://doi.org/10.5067/MODIS/MOD13A3.006

18. Dixon, R. K., Solomon, A. M., Brown, S., Houghton, R. A., Trexier, M. C., \& Wisniewski, J. (1994). Carbon pools and flux of global forest ecosystems. Science, 263(5144), 185-190.

https://doi.org/10.1126/science.263.5144.185

19. Feldpausch, T. R., Phillips, O. L., Brienen, R. J. W., Gloor, E., Lloyd, J., Lopez-Gonzalez, G., ... Vos, V. A. (2016). Amazon forest response to repeated droughts. Global Biogeochemical Cycles, 30(7), 964982. https://doi.org/10.1002/2015GB005133

20. Glorot, X., Bordes, A., \& Bengio, Y. (2011, June). Deep sparse rectifier neural networks. In Proceedings of the fourteenth international conference on artificial intelligence and statistics (pp. 315-323).

21. Haynes, R. J. (1986). The decomposition process: mineralization, immobilization, humus formation, and degradation. Mineral nitrogen in the plant-soil system.,

$52-126$

. https://doi.org/10.1016/B978-0-12-334910-1.50006-6

22. Hengl, T., Mendes de Jesus, J., Heuvelink, G. B., Ruiperez Gonzalez, M., Kilibarda, M., Blagotić, A., ... Guevara, M. A. (2017). SoilGrids250m: Global gridded soil information based on machine learning. PLoS one, 12(2), e0169748. https://doi.org/10.1371/journal.pone.0169748

23. Huang, K., Yi, C., Wu, D., Zhou, T., Zhao, X., Blanford, W. J., ... Li, Z. (2015). Tipping point of a conifer forest ecosystem under severe drought. Environmental Research Letters, 10(2), 024011. https://doi.org/10.1088/1748-9326/10/2/024011 
24. Hubau, W., Lewis, S. L., Phillips, O. L., Affum-Baffoe, K., Beeckman, H., Cuní-Sanchez, A., ... Zemagho, L. (2020). Asynchronous carbon sink saturation in African and Amazonian tropical forests. Nature, 579(7797), 80-87. https://doi.org/10.1038/s41586-020-2035-0

25. Hursh, A., Ballantyne, A., Cooper, L., Maneta, M., Kimball, J., \& Watts, J. (2017). The sensitivity of soil respiration to soil temperature, moisture, and carbon supply at the global scale. Global Change Biology, 23(5), 2090-2103. https://doi.org/10.1111/gcb.13489

26. Janssens, I. A., Lankreijer, H., Matteucci, G., Kowalski, A. S., Buchmann, N., Epron, D., ... Valentini, R. (2001). Productivity overshadows temperature in determining soil and ecosystem respiration across European forests. Global change biology, 7(3), 269-278. https://doi.org/10.1046/j.13652486.2001.00412.x

27. Johnston, A. S., Meade, A., Ardö, J., Arriga, N., Black, A., Blanken, P. D., ... Venditti, C. (2021). Temperature thresholds of ecosystem respiration at a global scale. Nature Ecology \& Evolution, 5(4), 487-494. https://doi.org/10.1038/s41559-021-01398-z

28. Jung, M., Reichstein, M., Schwalm, C. R., Huntingford, C., Sitch, S., Ahlström, A., ... Zeng, N. (2017). Compensatory water effects link yearly global land $\mathrm{CO}_{2}$ sink changes to temperature. Nature, 541(7638), 516-520. https://doi.org/10.1038/nature20780

29. Kingma, D. P., \& Ba, J. (2014). Adam: A method for stochastic optimization. arXiv preprint arXiv:1412.6980.

30. Koven, C. D., Ringeval, B., Friedlingstein, P., Ciais, P., Cadule, P., Khvorostyanov,D., ... Tarnocai, C. (2011). Permafrost carbon-climate feedbacks accelerate global warming. Proceedings of the National Academy of Sciences, 108(36), 14769-14774. https://doi.org/10.1073/pnas.1103910108

31. Lawrence, I., \& Lin, K. (1989). A concordance correlation coefficient to evaluate reproducibility. Biometrics, 255-268. https://doi.org/10.2307/2532051

32. Lewis, S. L., Brando, P. M., Phillips, O. L., van der Heijden, G. M., \& Nepstad, D. (2011). The 2010 amazon drought. Science, 331(6017), 554-554. https://doi.org/10.1126/science.1200807

33. Lloyd, J., \& Taylor, J. A. (1994). On the temperature dependence of soil respiration. Functional ecology, 315-323. https://doi.org/10.2307/2389824

34. Li, G., Han, H., Du, Y., Hui, D., Xia, J., Niu, S., ... Wan, S. (2017). Effects of warming and increased precipitation on net ecosystem productivity: a long-term manipulative experiment in a semiarid grassland. Agricultural and Forest Meteorology, 232, 359-366.

https://doi.org/10.1016/j.agrformet.2016.09.004

35. Liu, J., Zhou, T., Luo, H., Liu, X., Yu, P., Zhang, Y., \& Zhou, P. (2021). Diverse Roles of Previous Years' Water Conditions in Gross Primary Productivity in China. Remote Sensing. 13(1), 58. https://dx.doi.org/10.3390/rs13010058

36. Luo, H., Zhou, T., Wu, H., Zhao, X., Wang, Q., Gao, S., \& Li, Z. (2016). Contrasting responses of planted and natural forests to drought intensity in Yunnan, China. Remote Sensing, 8(8), 635. https://doi.org/10.3390/rs8080635 
37. Luo, H., Zhou, T., Yi, C., Xu, P., Zhao, X., Gao, S., \& Liu, X. (2018). Stock volume dependency of forest drought responses in Yunnan, China. Forests, 9(4), 209. https://doi.org/10.3390/f9040209

38. Luyssaert, S., Inglima, I., Jung, M., Richardson, A. D., Reichstein, M., Papale, D.,... Janssens, I. A. (2007). $\mathrm{CO}_{2}$ balance of boreal, temperate, and tropical forests derived from a global database.Global change biology, 13(12), 2509-2537. https://doi.org/10.1111/j.1365-2486.2007.01439.x

39. Martínez-Vilalta, J., Sala, A., Asensio, D., Galiano, L., Hoch, G., Palacio, S., ...Lloret, F. (2016). Dynamics of non-structural carbohydrates in terrestrial plants:a global synthesis. Ecological Monographs, 86(4), 495-516. https://doi.org/10.1002/ecm.1231

40. Pastorello, G., Trotta, C., Canfora, E., Chu, H., Christianson, D., Cheah, Y. W.,... Law, B. (2020). The FLUXNET2015 dataset and the ONEFlux processing pipeline for eddy covariance data. Scientific data, 7(1), 1-27. https://doi.org/10.6084/m9.figshare.12295910

41. Pregitzer, K. S., \& Euskirchen, E. S. (2004). Carbon cycling and storage in world forests: biome patterns related to forest age. Global change biology, 10(12), 2052-2077.

https://doi.org/10.1111/j.1365-2486.2004.00866.x

42. Rahman, M., Islam, M., Gebrekirstos, A., \& Bräuning, A. (2019). Trends in tree growth and intrinsic water-use efficiency in the tropics under elevated $\mathrm{CO}_{2}$ and climate change. Trees, 33(3), 623-640. https://doi.org/10.1007/s00468-019-01836-3

43. Raich, J. W., Rastetter, E. B., Melillo, J. M., Kicklighter, D. W., Steudler, P. A.,Peterson, B. J., ... Vorosmarty, C. J. (1991). Potential net primary productivity in South America: application of a global model. Ecological applications, 1(4), 399-429. https://doi.org/10.2307/1941899

44. Reich, P. B., Sendall, K. M., Stefanski, A., Wei, X., Rich, R. L., \& Montgomery, R. A. (2016). Boreal and temperate trees show strong acclimation of respiration to warming. Nature, 531(7596), 633-636. https://doi.org/doi:10.1038/nature17142

45. Reichstein, M., Camps-Valls, G., Stevens, B., Jung, M., Denzler, J., \& Carvalhais, N. (2019). Deep learning and process understanding for data-driven Earth system science. Nature, 566(7743), 195204. https://doi.org/10.1038/s41586-019-0912-1

46. Running, S. W., \& Hunt Jr, E. R. (1993). Generalization of a forest ecosystem process model for other biomes, BIOME-BCG, and an application for global-scale models. http://dx.doi.org/10.1016/B978-012-233440-5.50014-2

47. Running, S., Zhao, M. (2019). MOD17A3HGF MODIS/Terra Net Primary Production Gap-Filled Yearly L4 Global 500 m SIN Grid V006 [Data set]. NASA EOSDIS Land Processes DAAC. Accessed 2021-0917 from https://doi.org/10.5067/MODIS/MOD17A3HGF.006

48. Schwalm, C. R., Williams, C. A., Schaefer, K., Arneth, A., Bonal, D., Buchmann, N.,... Richardson, A. D. (2010). Assimilation exceeds respiration sensitivity to drought:A FLUXNET synthesis. Global Change Biology, 16(2), 657-670. https://doi.org/10.1111/j.1365-2486.2009.01991.x

49. Shi, Z., Thomey, M. L., Mowll, W., Litvak, M., Brunsell, N. A., Collins, S. L., ...Luo, Y. (2014). Differential effects of extreme drought on production and respiration:synthesis and modeling analysis. Biogeosciences, 11(3), 621-633. https://doi.org/10.5194/bg-11-621-2014 
50. Stocker, T. (Ed.). (2014). Climate change 2013: the physical science basis: Working Group I contribution to the Fifth assessment report of the Intergovernmental Panel on Climate Change. Cambridge university press.

51. Sulla-Menashe, D., \& Friedl, M. A. (2018). User guide to collection 6 MODIS land cover (MCD12Q1 and MCD12C1) product. USGS: Reston, VA, USA, 1-18. https://doi.org/10.5067/MODIS/MCD12Q1.006

52. Trumbore, S. (2006). Carbon respired by terrestrial ecosystems-recent progress and challenges. Global Change Biology, 12(2), 141-153. https://doi.org/10.1111/j.1365-2486.2006.01067.x

53. Turubanova, S., Potapov, P. V., Tyukavina, A., \& Hansen, M. C. (2018). Ongoing primary forest loss in Brazil, Democratic Republic of the Congo, and Indonesia. Environmental Research Letters, 13(7), 074028. https://doi.org/10.1088/1748-9326/aacd1c

54. van der Molen, M. K., Dolman, A. J., Ciais, P., Eglin, T., Gobron, N., Law, B. E.,... Wang, G. (2011). Drought and ecosystem carbon cycling. Agricultural and Forest Meteorology, 151(7), 765-773. https://doi.org/10.1016/j.agrformet.2011.01.018

55. van der Sleen, P., Groenendijk, P., Vlam, M., Anten, N. P., Boom, A., Bongers, F.,... Zuidema, P. A. (2015). No growth stimulation of tropical trees by 150 years of $\mathrm{CO}_{2}$ fertilization but water-use efficiency increased. Nature geoscience, 8(1), 24-28. https://doi.org/10.1038/NGEO2313

56. Verburg, P. S., Larsen, J., Johnson, D. W., Schorran, D. E., \& Arnone III, J. A. (2005). Impacts of an anomalously warm year on soil $\mathrm{CO}_{2}$ efflux in experimentally manipulated tallgrass prairie ecosystems. Global Change Biology, 11(10), 1720-1732. https://doi.org/10.1111/j.13652486.2005.001032.x

57. Vicente-Serrano, S. M., Gouveia, C., Camarero, J. J., Beguería, S., Trigo,R., López-Moreno,J. I.,... Sanchez-Lorenzo, A. (2013). Response of vegetation to drought time-scales across global land biomes. Proceedings of the National Academy of Sciences, 110,52-57. https://doi.org/10.1073/pnas.1207068110

58. Xiao, J., Chevallier, F., Gomez, C., Guanter, L., Hicke, J. A., Huete, A. R., ... Zhang,X. (2019). Remote sensing of the terrestrial carbon cycle: A review of advances over 50 years. Remote Sensing of Environment, 233, 111383. https://doi.org/10.1016/j.rse.2019.111383

59. Xiao, Z., Liang, S., Wang, J., Chen, P., Yin, X., Zhang, L., \& Song, J. (2014). Use of general regression neural networks for generating the GLASS leaf area index product from time-series MODIS surface reflectance. IEEE Transactions on Geoscience and Remote Sensing, 52(1), 209-223. https://doi.org/10.1109/TGRS.2013.2237780

60. Xiao, Z., Liang, S., Sun, R., Wang, J., \& Jiang, B. (2015). Estimating the fraction of absorbed photosynthetically active radiation from the MODIS data based GLASS leaf area index product. Remote Sensing of Environment, 171, 105-117. https://doi.org/10.1016/j.rse.2015.10.016

61. Xiao, Z., Liang, S., Wang, J., Xiang, Y., Zhao, X., \& Song, J. (2016). Long-time-series global land surface satellite leaf area index product derived from MODIS and AVHRR surface reflectance. IEEE Transactions on Geoscience and Remote Sensing, 54(9), 5301-5318. https://doi.org/10.1109/TGRS.2016.2560522 
62. Xu, L., Baldocchi, D. D., \& Tang, J. (2004). How soil moisture, rain pulses, and growth alter the response of ecosystem respiration to temperature. Global Biogeochemical Cycles, 18(4). https://doi.org/10.1029/2004GB002281

63. Yvon-Durocher, G., Caffrey, J. M., Cescatti, A., Dossena, M., Del Giorgio, P., Gasol,J. M., ... Allen, A. P. (2012). Reconciling the temperature dependence of respiration across timescales and ecosystem types. Nature, 487(7408), 472-476. https://doi.org/10.1038/nature11205

64. Yuste, J. C., Nagy, M., Janssens, I. A., Carrara, A., \& Ceulemans, R. (2005). Soil respiration in a mixed temperate forest and its contribution to total ecosystem respiration. Tree physiology, 25(5), 609-619.

\section{Declarations}

\section{Acknowledgements}

We thank all data provider for FLUXNET2015 dataset, CRU meteorological dataset, remote sensing dataset and soil organic carbon dataset. We would like to thank the high-performance computing support from the Center for Geodata and Analysis, Faculty of Geographical Science, Beijing Normal University [https://gda.bnu.edu.cn/]. This work was supported by the second Tibetan Plateau Scientific Expedition and Research Program (2019QZKK0405) and the National Natural Science Foundation of China (41571185).

\section{Author's contributions}

Peixin Yu processed the data and designed the experiment. Peixin Yu and Tao Zhou performed the data analysis and drafted the manuscript. Hui Luo, Xia Liu, Jingzhou Zhang, Yajie Zhang, Peifang Zhou and Yixin Xu participated in discussions and review. Peijun Shi provided useful comments. All authors contributed to the manuscript and approved the final version.

\section{Competing interests}

The authors declare no competing interests.

\section{Figures}

\section{Figure 1}

Multi-year average and standard deviation of global RECO spatial distribution from 2000 to 2018. (a) Multi-year average CNN-SPElopt RECO from 2000 to 2018; bar chart at the bottom right is the average RECO from 2000 to 2010 simulated by models. (b) Standard deviation of CNN-SPElopt RECO from 2000 to 2018; bar chart at the bottom right is the standard deviation of RECO from 2000 to 2010 simulated by 
models. The percentages above the columns are the ratio of other models' values that are higher or lower than the value of CNN-SPElopt.

Figure 2

Validation results of the models.
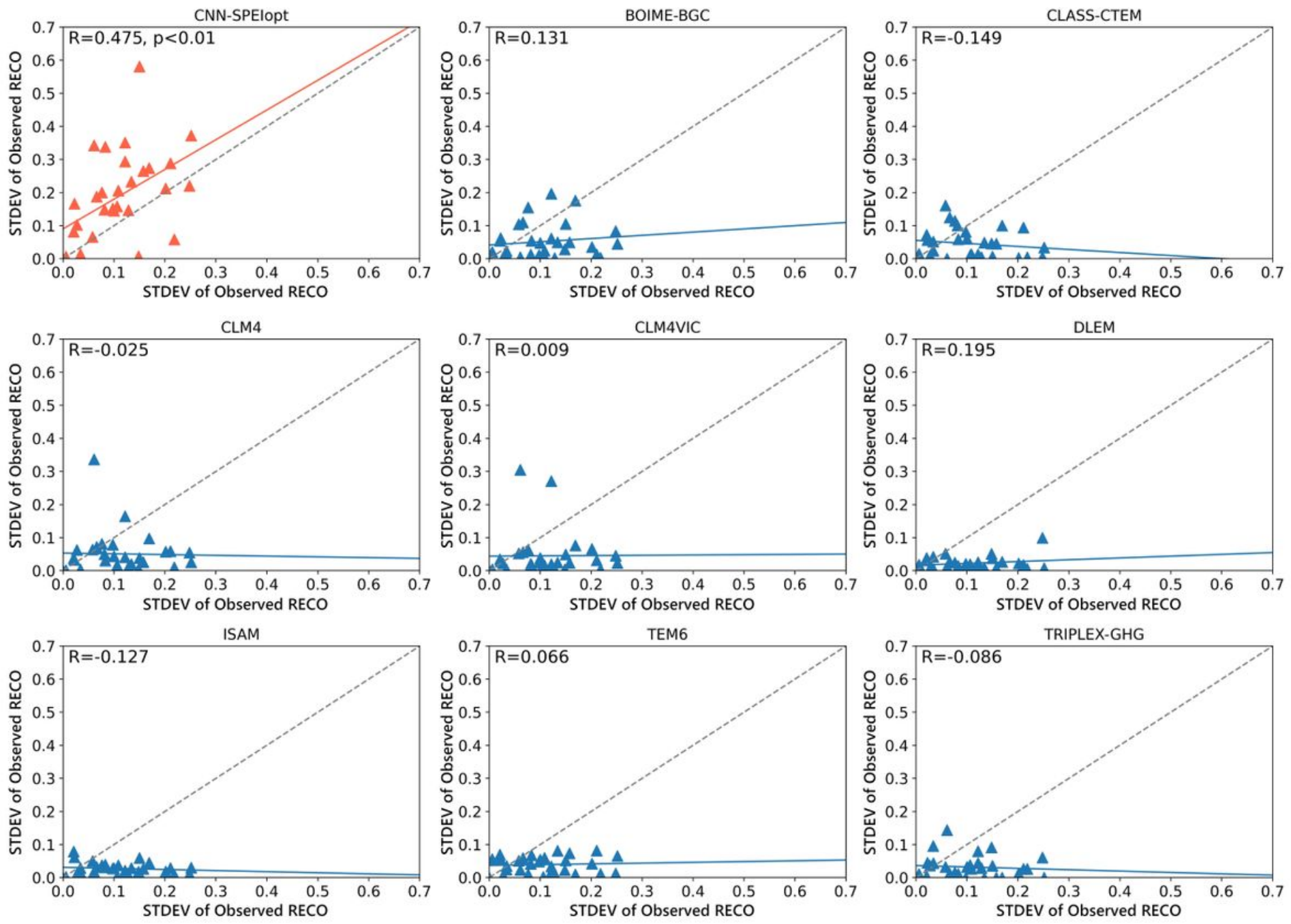

\section{Figure 3}

Correlation analysis of the standard deviation between observations and simulated values. 
(a) Global

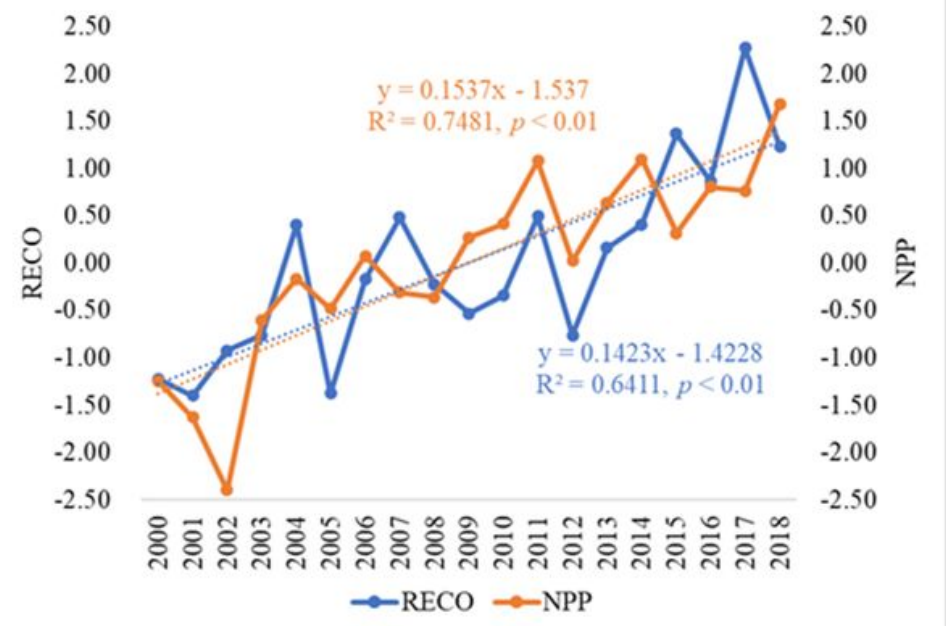

(c) Tropics

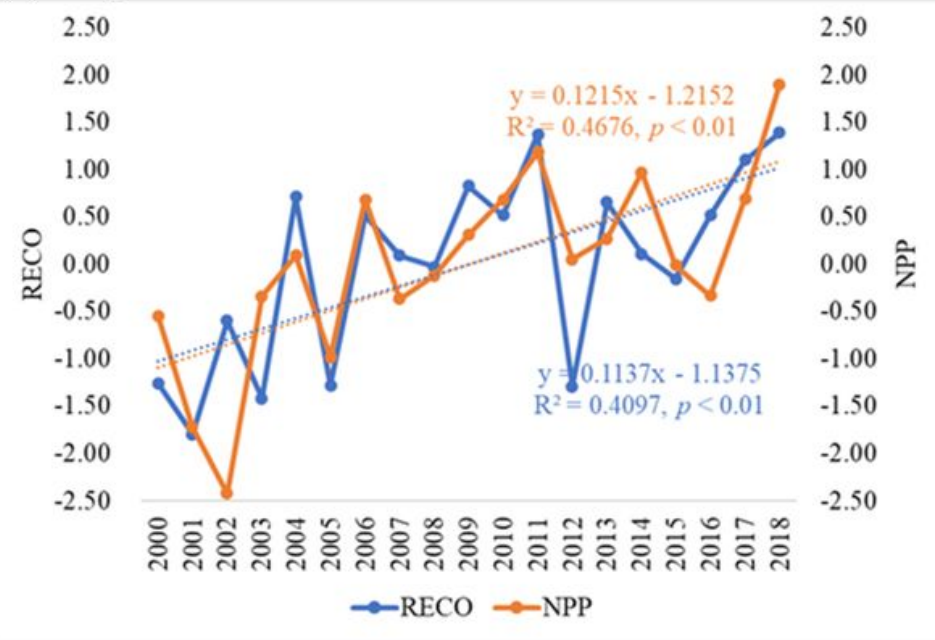

(b) Northern extra-tropics

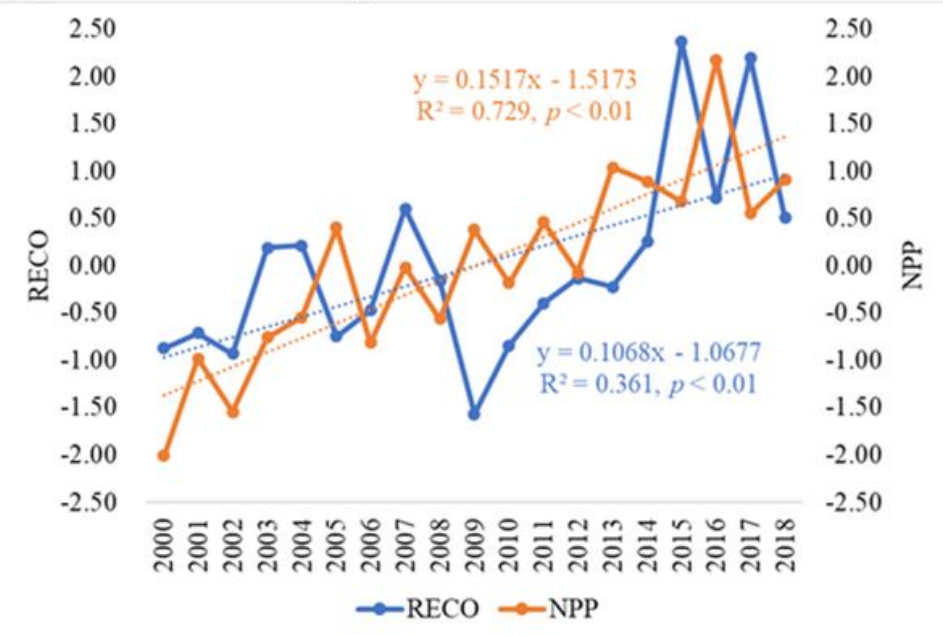

(d) Southern extra-tropics

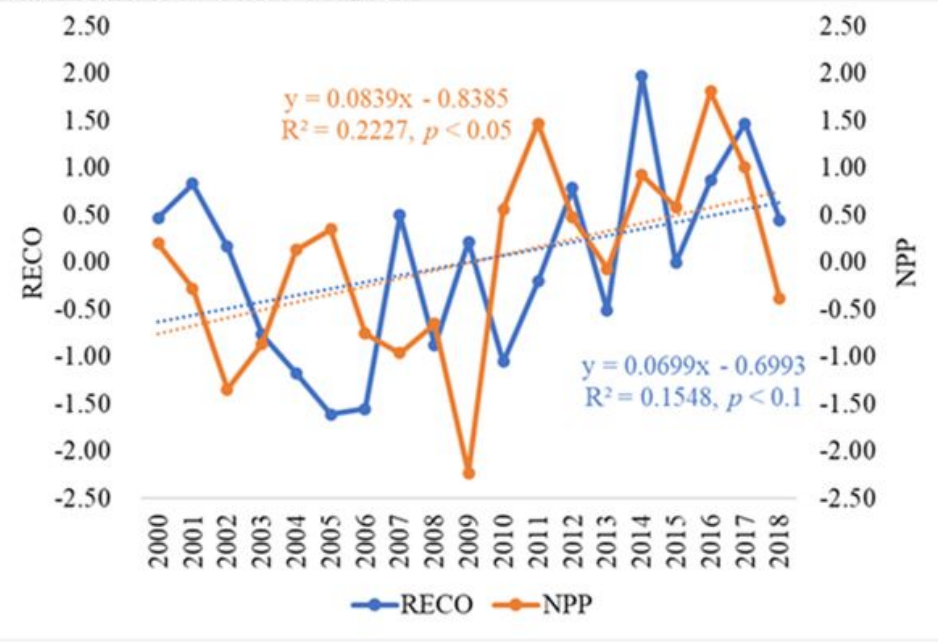

\section{Figure 4}

Global and regional interannual variations of RECO and NPP. 
(a) Growth rate of RECO

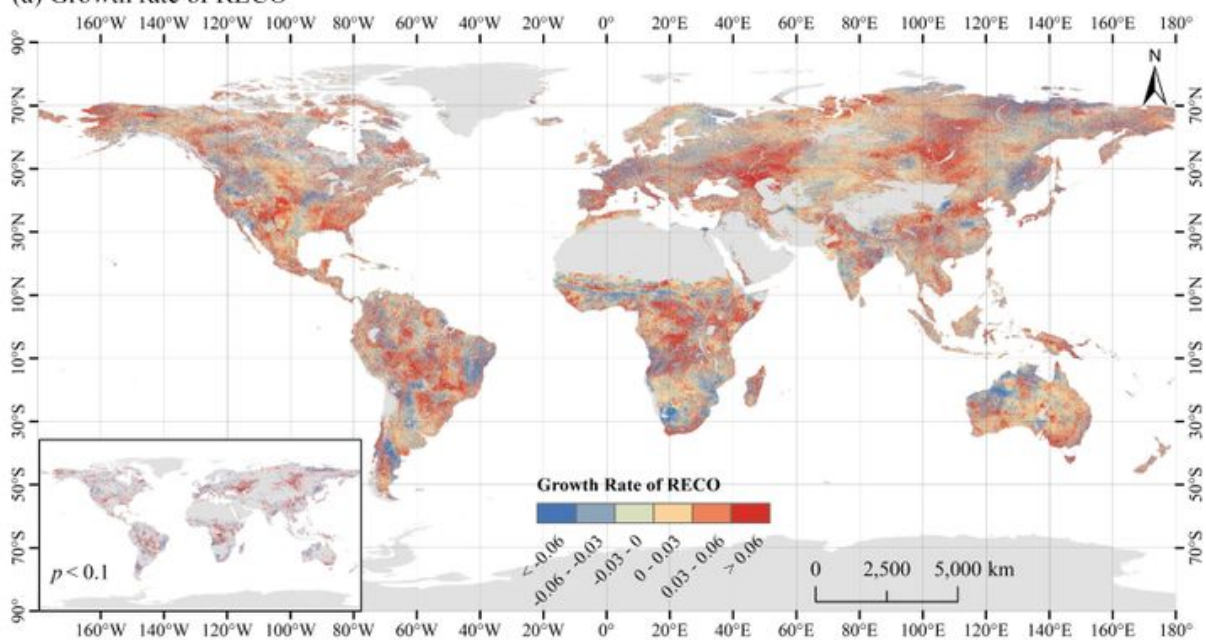

(b) Growth rate of NPP

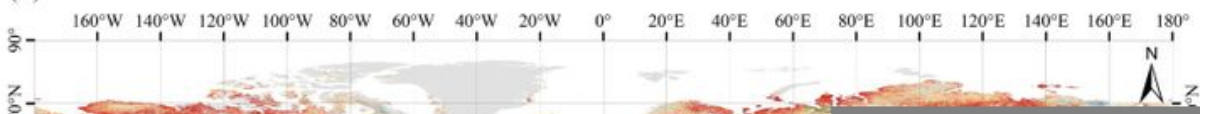

\section{Figure 5}

Spatial distribution of global RECO and NPP change trends. (a) and (b) are the spatial distributions of global RECO and NPP growth rates, respectively. Figures in the lower left boxes show the growth rates of RECO/NPP significantly at $p<0.1$ level. (c) is the spatial distribution of global RECO and NPP change directions. 


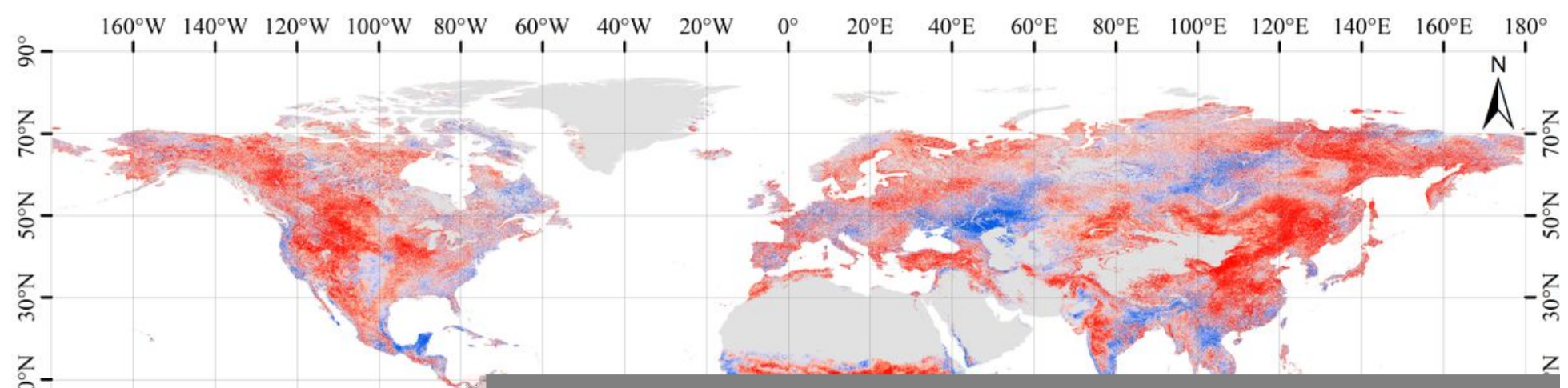

Figure 6

Difference between the NPP and RECO growth rates.

Figure 7

Regional carbon sink capacity assessment. (a) Carbon sink potential of major vegetation types, which are derived from 2018 MCD12C1v006 product (Sulla-Menashe \& Friedl., 2018). (b) Carbon sink potential of several economies. Horizontal coordinate indicates the proportion of area where the growth rate of NPP is higher than the growth rate of RECO; vertical coordinate is the proportion of area where the growth rate of RECO is higher than the growth rate of NPP; the size of the circle indicates the size of the area of each country or region. The closer to the lower right corner of the graph indicates that the carbon sink capacity is larger, and the closer to the upper left corner indicates that the carbon sink capacity is smaller. 